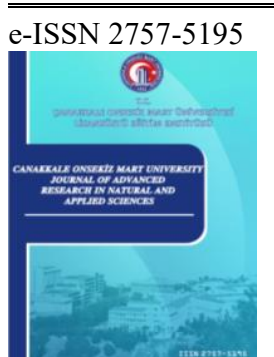

Çanakkale Onsekiz Mart University

Journal of Advanced Research in Natural and Applied Sciences

Open Access

\title{
Monte Carlo Simulation of the Gamma-Ray Transmissions for the newly Designed Shielding Blocks used in Radiotherapy
}

\begin{abstract}
Nuray Yavuzkanat ${ }^{1, *}$, Hazal Burcu Saraç Kürem²
${ }^{1}$ Physics Department, Faculty of Art and Sciences, Bitlis Eren University, Bitlis, Turkey

${ }^{2}$ Physics Department, Graduate Education Institute, Bitlis Eren University, Bitlis, Turkey

Article History

Received: $\quad 15.06 .2020$

Accepted: $\quad 08.12 .2020$

Published: $\quad 29.12 .2020$

Research Article

Abstract - Radiotherapy is one of the most important treatment methods of cancer, which is the worldwide disease nowadays. It is essential to protect the critical organs and healthy tissue inside the radiated area during the radiotherapy. For this reason, Cerrobend block (lipowitz alloy), which is made specifically for each patient, are commonly used in the hospitals. In the clinical application, the acceptable level of the gamma-ray transmission for Cerrobend blocks must be less than 5\%. In this research, GEANT4 based GATE simulation program modelled to compare between gamma-ray transmissions of the standard Cerrobend block and newly designed Cerrobend blocks formed by adding the various number of the pure lead marbles. Experimental measurements were carried out with Alcyon II model Co-60 teletherapy machine for various field sizes by using Farmer type 0,6 cc ion chamber, PTW Unidos Dosimeter and solid phantom in Dr. Abdurrahman Yurtaslan Ankara Oncology Training and Research Hospital in 2010. The gamma-ray transmission of the newly designed Cerrobend block was found less than the standard block, therefore the protection of the critical organs for the patient could be better. The dose acquired by GEANT4 based GATE simulation program is consistent in experimentally measured radiation dose. Furthermore, the values of the linear attenuation coefficient theoretically obtained from XCOM software agree with the values acquired by experiment and simulation.
\end{abstract}

Keywords - Cerrobend, GATE simulation, mass attenuation coefficient, radiotherapy, shielding block

\section{Introduction}

Radiotherapy is one of the most important treatment methods of cancer, which is the worldwide disease nowadays. The purpose of the radiotherapy is giving the sufficient dose to the target volume (benign tumour or cancer cells) and the lowest dose to the critical organ, healthy tissue or system which is surrounding with tumour (such as the brain and lymphatic system) (Jeraj \& Robar, 2004; Chang, Zhang, Dong, Zhang \& Dai, 2012). If there is a virtual organ inside the radiation field, it is necessary to use a shielding block to protect it from the undesirable radiation. Determination of the perfect shape of the beam is the major step to minimise the amount of the absorbed dose in healthy tissue and critical structure in the field (Jeraj et al., 2004). There are two appropriate ways to shape the beam field in radiation therapy. In modern radiotherapy, MLC (Multileaf Collimator or beam-limiting device) is used to obtain the conformal shaping of the radiation field and it is suitable for IMRT (inserted modulated radiotherapy) and conformal radiotherapy (Jeraj et al., 2004; Farajollahi, Bouzarjomehri, \& Kiani, 2015). MLC is controlled by the computer and using them reduces the treatment time, transfers the treatment information, and provides a clean environment. However, they are not only expensive, but they have also complicated software for technicians (Taherkhani, Mohammadi, Saboori, \& Changizi, 2010). Another method is using the shielding blocks which are placed under the primary collimator system and attached into the head of the treatment machine (Jeraj et al., 2004). In order to minimize the damage, to healthy tissue and reduce the potential side-effect of the radiation on living, must be used the shielding blocks with proper dimension and appropriate material (Tellili, Elmahroug, \& Souga, 2017). Standard lead blocks in the clinic have a regular shape like cubic, pyramidal and cylindrical having thickness

\footnotetext{
1 nyavuzkanat@beu.edu.tr

2 (i) hazalbrc@gmail.com

*Corresponding Author
} 
proportional with the energy of the incident photon (Farajollahi et al., 2015). However, it could be not suitable to use them due to the irregular shape of the tumour region inside the beam field of some patient. For this reason, the irregular shape of the shielding blocks depends on the cancer regions of each patient, must be formed individually in the hospital. Standard lead blocks have not beam divergent, therefore they produce higher penumbra compared to shielding block called Cerrobend alloy (Farajollahi et al., 2015). The penumbra area created with MLC is also generally reported to be larger than the penumbra region generated by Cerrobend (Taherkhani et al., 2010). Instead of standard lead blocks must be used mould blocks to exactly protect critical organs (Alkaya, Baş, Gürsoy, \& Kemikler, 2000). In practice, it is not convenient to use pure lead as a moulding block due to its higher melting point $\left(327^{\circ} \mathrm{C}\right)$. Desirable shielding material should include lead (heavy metal) to absorb the radiation and should have a lower melting temperature for being practical during the clinical application. Lipowitz alloy, which was used in hospitals in the past, consists of 50\% bismuth, $26.7 \%$ lead, $13.3 \%$ tin and $10 \%$ cadmium and has a low melting point. However, today Cerrobend alloy is used as a mould block and its lower melting point (only $95^{\circ} \mathrm{C}$ ). Cerrobend consists of $50 \%$ bismuth, 31.8\% lead and $18.2 \%$ tin elements without cadmium because of its poison effects. Normal tissues or critical organs around the tumour and under the shielding blocks receive a lower radiation dose as a result of using Cerrobend blocks (Alkaya et al., 2000; Davis, \& Reiner, 1995; Farajollahi et al., 2015). It is broadly making individual Cerrobend shielding blocks in our country and several countries, because of the rare of the accelerator with MLC and the other disadvantages of using MLC (Farajollahi et al., 2015). Therefore, these blocks are widely used in radiation oncology centres to protect normal tissues and critical organs (Taherkhani et al., 2010). Cerrobend block thickness is commonly chosen to reduce the dose under the block by $95-98 \%$ of the open beam dose (Farajollahi et al., 2015; Di Venanzio et al., 2015). In other words, the acceptable level of the radiation transmission for Cerrobend blocks is less than 5 percentages (Farajollahi et al., 2015). One experimental research in Iran was performed to compare the influence of the standard lead blocks and Cerrobends on the radiation dose for 23 different radiation field sizes at the depth from 0.5 to $20 \mathrm{~cm}$ (Farajollahi et al., 2015). As a result, there is no significant difference between standard lead block and Cerrobend shielding method in terms of the percent dose distribution of the photon beam on the central axis (Farajollahi et al., 2015). Furthermore, Cerrobend alloy is preferred to use in the clinics because of its lower melting point, more rigid at the room temperature, the high attenuation coefficient of the photon beam, non-toxicity, easy and fast fabrication technique. The electron beam therapy is commonly applied for treating skin, superficial tumours and the tumours at the depth of less than $0.5 \mathrm{~cm}$ under the skin (Chang et al., 2012). According to the shape of the tumour, electron beam collimator is generally achieved using standard Cerrobend block attached to the accelerator head (Di Venanzio et al., 2015). It is a challenge to calculate dose distribution under the protection block for electron beam therapy (because of the electron scattering changes with the alloy density and composition) (Chang et al., 2012). Wojcicka, Yankelevich, Werner and Lasher (2008) concluded that acceptable level of the transmission (5\%) for Cerrobend blocks was not achievable with a standard thickness of the block for electron beam energies $18 \mathrm{MeV}$ and greater, because of the bremsstrahlung production in Cerrobend alloy (Wojcicka et al., 2008). During the high energy electron beam treatment, it is required to use extra shielding to reduce the transmission level and providing better protection (Wojcicka et al., 2008).

In radiation therapy, a significantly important part of the planning process is accurately calculation of the radiation dose in the patient and absorbed dose distribution through the interested tissues and organs (Chang et al., 2012; Sarrut et al., 2014). Monte Carlo (MC) technique correctly provides the ionizing radiation transportation, dose and dose distribution in a complicated configuration such as detectors, Linear Accelerators (Linacs), and phantoms etc. (Chang, et al., 2012; Sarrut et al., 2014; Oliveira, Vieira, Santana, \& Lima, 2013). Many algorithms, based on the Monte Carlo calculation over the last decade, improved with providing very encouraging results in terms of accuracy and more realistic results (Oliveira et al., 2013). MC simulation is good at the calculation of the energy deposition for various components in its sensitive volume which is the alternative of the ionizing chamber configuration (Perini et al., 2013). In the literature, there are many kinds of research about the determination of shielding material properties completed by MCNP-X simulation code 
and compared with XCOM data (Perini et al., 2013; Reda, 2016; Tekin et al., 2018, Tekin, \& Manici, 2017). Limited studies are fulfilled in Geant4 based GATE (Geant4 Application for Tomographic Emission) simulation to investigate new shielding materials. GATE simulation code is one of the open source Monte Carlo calculation software developed by international collaborations (URL-1, 2018). It is dedicated to the application field especially, medical physics, radiology, and radiotherapy (Sarrut et al., 2014). In today, GATE simulation is widely used in developing new medical devices, quality control protocols, and medical imaging systems etc. (Sarrut et al., 2014; Oliveira et al., 2013; URL-1, 2018; Aguwa, 2015). This research aims to provide better critical organs protection and avoid delivering unnecessary dose to healthy tissues or organs. In this study, a new designed Cerrobend block was made by adding the different number of the pure lead marbles into the Cerrobend mould. Radiation dose under the standard Cerrobend block was compared with the newly designed protection blocks to investigate of their shielding capacitance. Experimental measurements were carried out with Alcyon II model Co-60 teletherapy machine under the various field size by using Farmer type $0.6 \mathrm{cc}$ ion chamber, PTW Unidos Dosimeter, and solid phantom in Dr. Abdurrahman Yurtaslan Ankara Oncology Training and Research Hospital. For comparison, the dose values were also obtained by using the Geant 4 based GATE simulation program. The attenuation data of the common shielding materials are available at the National Institute of the Standards (NIST) XCOM (McAlister, 2018; Seenappa, Manjunatha, Chandrika, \& Chikka, 2017; Mostafa, Issa, \& Sayyed, 2017; Yorgun, 2019). Online software calculates the mass attenuation coefficient for alloy and mixture of the material (Erk, Altınsoy, Karaaslan, \& Bora, 2016; Tarım, \& Gürler, 2018; Ozyurt et al., 2018). In addition to the simulation, the values of the linear attenuation coefficient for each block were calculated from the XCOM software. Therefore, the simulated shielding properties were compared with experimental results and XCOM data values. According to the results, a newly designed shielding block (Block 7) could be preferred to accurately protect the critical organ or healthy tissues against the gamma radiation during the radiotherapy. In addition, more research could be carried out to investigate how changing the dose distribution under new designed Blocks in terms of the electron scattering in electron beam therapy.

\section{Materials and Methods}

\subsection{Theoretical Calculation}

\subsubsection{Total Mass and Linear Attenuation Coefficient}

When incoming gamma-rays passage through the material medium, photons undergo the several interactions with material such as photoelectric effect, Compton scattering, coherent and incoherent scattering and pair production. In theory, the best protection block (or shielding material) should be $100 \%$ absorbed the incoming radiation. However, in practice it is impossible, because the radiation attenuation decreases exponentially as described by the following equation and it is called Beer-Lambert law (Yavuzkanat, 2010);

$$
\mathrm{I}=\mathrm{I}_{0} e^{-\left(\mu_{m} \cdot \rho \cdot x\right)} \text { or } \mathrm{I}=\mathrm{I}_{0} e^{-(\mu \cdot x)}
$$

Where $\mathrm{I}$ is the intensity of the gamma-ray after passing through the shielding block, $\mathrm{I}_{0}$ incident gamma ray's intensity, $\mu_{\mathrm{m}}$ is the mass absorption coefficient $\left(\mathrm{cm}^{2} / \mathrm{g}\right), \rho$ is the density of the shielding material $\left(\mathrm{g} / \mathrm{cm}^{3}\right)$ and $\mathrm{x}$ is the shielding thickness $(\mathrm{cm})$. The total mass attenuation coefficient defines the interaction probability between incoming photons and the thickness of the shielding material. If the target material is mixture or compound, the mass attenuation coefficient could be calculated by the following equation according to the mixture law (Yavuzkanat, 2010);

$$
\mu_{m}=\frac{\mu}{\rho}=\sum W_{i}\left(\frac{\mu_{i}}{\rho_{i}}\right)
$$


Where $\mathrm{W}_{\mathrm{i}}$ is the weight fraction of and $\mu\left(\mathrm{cm}^{-1}\right)$ represents the linear attenuation coefficient of the constituent element $i^{\text {th }}$.

\subsubsection{The Mean Free Path}

The mean free path $(\lambda)$ is defined as the average distance at which the photon passes through the material before it collides. The linear attenuation coefficient $(\mu)$ is inversely proportional to the mean free path and is related as follows (Yavuzkanat, 2010);

$$
\lambda_{(\text {mean free path })}=\frac{1}{\mu}
$$

\subsubsection{Absorbed Dose in GATE}

Absorbed dose, $\mathrm{D}$, is defined as the deposited energy per unit mass of the material in units of Gray ( $1 \mathrm{~Gy}=1$ $\mathrm{J} / \mathrm{kg}$ ) (Sarrut et al., 2014). In Monte Carlo calculation deposited energy, $E_{\text {dep }}$, in a volume is generally expressed in $\mathrm{eV}\left(1 \mathrm{eV}=1.60217 \times 10^{-19} \mathrm{~J}\right)$ (Sarrut et al., 2014; URL-1, 2018). According to the medium volume (V) and density ( $\rho$ ), deposited energy converts to the Gray (Gy) as expressed in the following equation (Sarrut et al., 2014; URL-1, 2018),

$$
\mathrm{D}=\frac{E_{\text {dep }} 1.60217 \times 10^{-19}}{\rho / V}
$$

Though absorbed dose does not reflect the biological effects of the radiation, it is the first step toward the assessment of the biological impact. Absorbed dose in a given volume in a 3D matrix is stored by "DoseActor" mechanism which has to be attached with interested volume. Deposited energy and absorbed dose are calculated by the Actor in the unit of $\mathrm{MeV}$ and Gy respectively.

\subsection{Experimental and Simulated Methods}

\subsubsection{Experimental Set-up and Measurement}

Experimental measurements were performed in Alcyon II model Co- 60 teletherapy machine with $0^{\circ}$ gantry and collimator angles. The room temperature and pressure were measured as 20 degrees and 1013 mbar respectively. The correction factor was set to one to find the absorbed dose. In Figure 1.(a), it is shown the experimental set-up for unblocked open field radiation dose measurement to find the incident radiation intensity before the interaction with the shielding material. As seen in Figure 1.(b), the shielding block tray was set to in front of the Co-60 machine primary collimator to investigate the influence of different shielding blocks on the central axis dose.

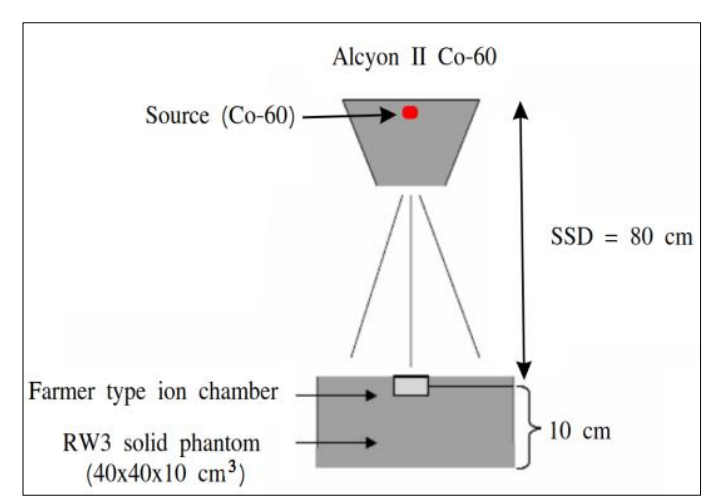

(a)

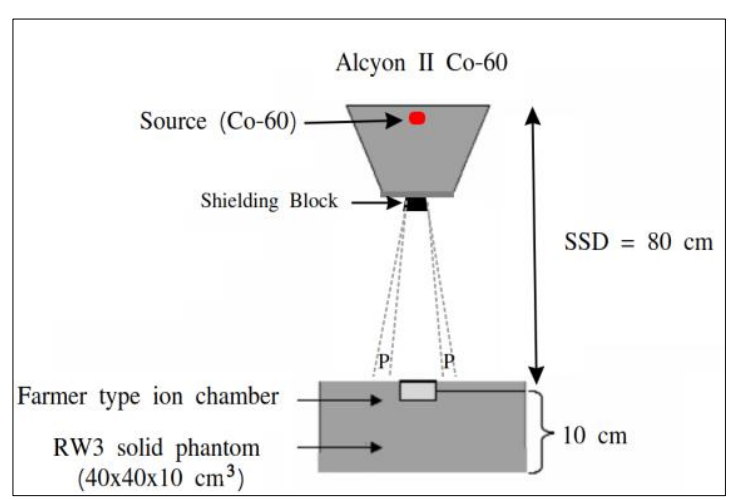

(b) 
Figure 1. (a) unblocked open field measurement set-up which is completed to find out the incident radiation intensity $\left(\mathrm{I}_{0}\right)$ before the interaction with shielding material (Yavuzkanat, 2010; Kürem, 2020). (b) Experimental set-up of the radiation dose measurement to investigate the influence of the different shielding blocks on the central axis dose distribution. $\mathrm{P}$ areas are called penumbra due to the block divergent.

Farmer-2571 type detector (ion chamber), with $6.3 \mathrm{~mm}$ inner diameter and $0.6 \mathrm{~cm}^{3}$ active volume, was put inside the solid phantom. RW3 solid phantom with $1.045 \mathrm{~g} / \mathrm{cm}^{3}$ density and 40x40x10 $\mathrm{cm}^{3}$ volume, was placed on the treatment couch with its central axis set perpendicular to the beam axis. Ionization chamber was positioned at $80 \mathrm{~cm}$, which is the standard treatment distance of Co-60 machine, and called SSD (Source to Surface Distance). Measurements were completed for nine different radiation field sizes from $4 \times 4$ to $20 \times 20$ $\mathrm{cm}^{2}$.

\subsubsection{Preparation of the Shielding Blocks}

Seven different blocks were designed with similar geometrical shape (the truncated square pyramid) having $6 \mathrm{~cm}$ thickness and similar blocks are also modelled in Geant4 based GATE simulation program as shown in Figure 2.

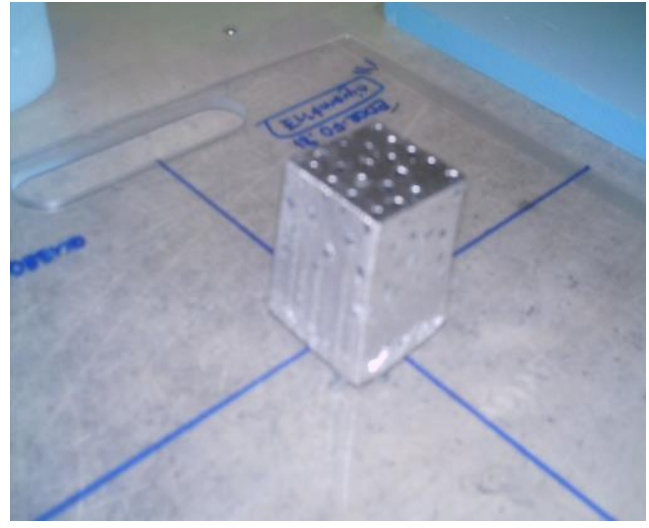

(a) Prepeared cerrobend block.

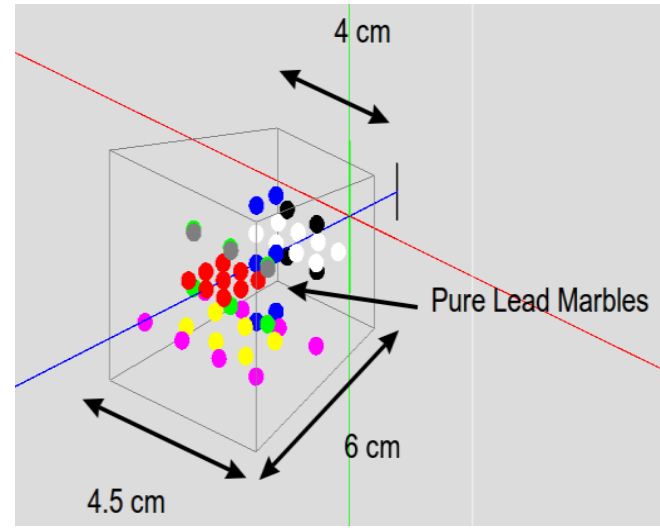

(b) Simulated cerrobend block.

Figure 2. The truncated square pyramid shape of the Cerrobend blocks with $6 \mathrm{~cm}$ thickness. Pure lead marbles were randomly added into the hot liquid Cerrobend metal for each different shielding block from Block 2 to 7 as given in Table 1. Block 1 is made without lead marbles. (a) Prepared Cerrobend block with adding 60 pure lead marbles into the Cerrobend alloy (Yavuzkanat, 2010; Kürem, 2020). (b) The same block visualizes in the GATE simulation program.

The outline of the block shape was transferred to the computer and then, Styrofoam cutting system cut the styrofoam automatically. Hot liquid Cerrobend metal was poured inside the styrofoam casting, then waited until completely cool down. Styrofoam was broken and cold blocks were designed with steep edges to make a similar to the beam divergent. The top and base side lengths of the truncated pyramid were 4 and $4.5 \mathrm{~cm}$ respectively because of the source divergent. Each block was attached to the Plexiglas tray in order to insert into the head of the Co-60 machine. Block1 was made without adding lead marbles and other blocks were formed with marbles putting randomly into the Cerrobend increasing by ten as listed in Table 1 . The chemical and physical properties of the Cerrobend alloy were also determined inside the GATE simulation material file according to the GEANT4 format. The lead marbles were placed inside the Cerrobend volume (truncated square pyramid) defined in the world and the number of the marbles was increased ten by ten from Block 2 to Block 7 similar to experiment. In Figure 2 (b), sixty lead marbles were randomly inserted inside the truncated square pyramid volume defined as a Cerobend alloy. Eight different shielding blocks were determined in the GATE simulation. 
Table 1

Blocks were formed by adding different number of lead marbles (from 10 to 60) in the experiment and GATE simulation. The marbles were randomly put into hot Cerrobend mould.

\begin{tabular}{|c|c|c|c|c|c|c|c|}
\hline & Block 1 & Block 2 & Block 3 & Block 4 & Block 5 & Block 6 & Block 7 \\
\hline $\begin{array}{c}\text { Number of } \\
\text { marbles }\end{array}$ & $\begin{array}{c}\text { No } \\
\text { marbles }\end{array}$ & 10 & 20 & 30 & 40 & 50 & 60 \\
\hline
\end{tabular}

\subsubsection{Gamma-ray Transmission Measurement and Simulation for Various Radiation Field}

Source to surface distance was fixed to $80 \mathrm{~cm}$. The various regular radiation field sizes were used from $4 \times 4$ to $16 \times 16 \mathrm{~cm}^{2}$. Incident radiation dose $\left(\mathrm{I}_{0}\right)$ for every field size was measured without shielding block to determine the open field radiation dose. Then each different block for every field size was used to find out how the effect incoming radiation by the number of the pure lead marbles. Furthermore; experimental conditions and all the volumes were defined in the GATE simulation program as shown in Figure 3.

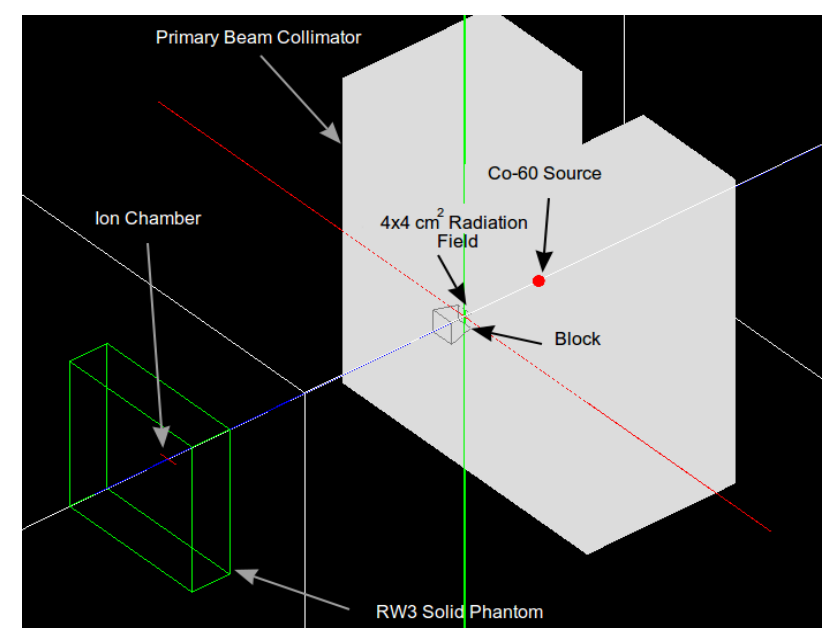

Figure 3. The visualization of the simulation setup and all the volumes were described in GATE. Solid phantom with ion chamber and cylindrical isotropic Co-60 radioactive source with primary beam collimator were shown in the figure. Before the shielding block, the radiation field at $4 \times 4 \mathrm{~cm}^{2}$ field size was opened by positioned primary collimator.

The volume of the Cobalt-60 source was described by a cylinder with 1.5 diameters and $1 \mathrm{~cm}$ length as illustrated in Figure 3 (in red colour) (Joshi, Darko, Vidyasagar, \& Schreiner, 2008; Han, Ballon, Chui, \& Mohan, 1987). The simulation was run with a discreet spectrum instead of the radioactive source decay for Co-60 (1.3325 MeV and 1.1732 MeV gamma rays) in order to speed up the simulation time. Solid Phantom volume was attached to the dose actor with 20x20x101 $\mathrm{mm}^{3}$ voxel size to obtain precisely dose output in a Gy unit. After defining volumes, source, and physics list, lastly the data output was defined as a txt format in DoseActor. In any Geant 4 simulation, sensitive detector concept allows the record the information regarding the interaction between particle and medium (called hits) (Perini et al., 2013; Ozyurt et al., 2018). In this simulation, solid phantom was determined as a sensitive volume.

\section{Results and Discussion}

Experimental and GATE simulation results were tabulated in Table 2. Each measurement during the experiment was repeated three times and the error was obtained not more than $0.1 \%$. In the simulation, three times data acquisition were achieved by using random number seeds. The average value and the standard deviation were calculated as given in Table 2. Seven different shielding blocks were used to investigate the influence of the number of the pure lead marbles on the radiation dose. It can be clearly seen in Figure 4 that 
the trends of the measured and simulated dose for each different field size depend on the concentration of the lead marbles within Cerrobend alloys.

Table 2

Dose values for each block at the various radiation field sizes, experimental and simulated results. The differences between simulated and measured values were calculated less than $3 \%$.

\begin{tabular}{|c|c|c|c|c|c|c|c|c|c|}
\hline \multicolumn{2}{|c|}{$\begin{array}{l}\text { Field Size } \\
\qquad\left(\mathrm{cm}^{2}\right)\end{array}$} & \multirow{2}{*}{$\begin{array}{c}\begin{array}{c}\text { Incoming } \\
\text { Radiation } \\
\text { Dose, } \mathbf{I}_{\mathbf{0}}(\mathbf{G y})\end{array} \\
0.5107\end{array}$} & \multirow{2}{*}{$\begin{array}{c}\begin{array}{c}\text { Block } 1 \\
\text { (Gy) }\end{array} \\
0.0175\end{array}$} & \multirow{2}{*}{$\begin{array}{c}\begin{array}{c}\text { Block } 2 \\
\text { (Gy) }\end{array} \\
0.0172\end{array}$} & \multirow{2}{*}{$\begin{array}{c}\begin{array}{c}\text { Block } 3 \\
\text { (Gy) }\end{array} \\
0.0168\end{array}$} & \multirow{2}{*}{$\begin{array}{c}\begin{array}{c}\text { Block } 4 \\
\text { (Gy) }\end{array} \\
0.0163\end{array}$} & \multirow{2}{*}{$\begin{array}{c}\begin{array}{c}\text { Block } 5 \\
\text { (Gy) }\end{array} \\
0.0157\end{array}$} & \multirow{2}{*}{$\begin{array}{c}\begin{array}{c}\text { Block 6 } \\
\text { (Gy) }\end{array} \\
0.0152\end{array}$} & \multirow{2}{*}{$\begin{array}{c}\text { Block } 7 \\
\text { (Gy) }\end{array}$} \\
\hline & Exp. & & & & & & & & \\
\hline $4 \times 4$ & GATE & $\begin{array}{c}0.51165 \\
\pm 0.00244\end{array}$ & $\begin{array}{c}0.01745 \\
\pm 0.00059\end{array}$ & $\begin{array}{c}0.01704 \\
\pm 0.00059\end{array}$ & $\begin{array}{c}0.01671 \\
\pm 0.00059\end{array}$ & $\begin{array}{c}0.01630 \\
\pm 0.00059\end{array}$ & $\begin{array}{c}0.01594 \\
\pm 0.00059\end{array}$ & $\begin{array}{c}0.01519 \\
\pm 0.00059\end{array}$ & $\begin{array}{c}0.01444 \\
\pm 0.00059\end{array}$ \\
\hline \multirow{2}{*}{$5 \times 5$} & Exp. & 0.5227 & 0.0182 & 0.0179 & 0.0175 & 0.0169 & 0.0163 & 0.0157 & 0.0150 \\
\hline & GATE & $\begin{array}{c}0.52038 \\
\pm 0.00380\end{array}$ & $\begin{array}{c}0.01816 \\
\pm 0.00067\end{array}$ & $\begin{array}{c}0.01774 \\
\pm 0.00067\end{array}$ & $\begin{array}{c}0.01741 \\
\pm 0.00067\end{array}$ & $\begin{array}{c}0.01698 \\
\pm 0.00067\end{array}$ & $\begin{array}{c}0.01661 \\
\pm 0.00067\end{array}$ & $\begin{array}{c}0.01584 \\
\pm 0.00067\end{array}$ & $\begin{array}{c}0.01507 \\
\pm 0.00067\end{array}$ \\
\hline \multirow{2}{*}{$6 \times 6$} & Exp. & 0.5297 & 0.0190 & 0.0186 & 0.0181 & 0.0175 & 0.0169 & 0.0162 & 0.0154 \\
\hline & GATE & $\begin{array}{c}0.53124 \\
\pm 0.00348\end{array}$ & $\begin{array}{c}0.01880 \\
\pm 0.00044\end{array}$ & $\begin{array}{c}0.01841 \\
\pm 0.00044\end{array}$ & $\begin{array}{c}0.01797 \\
\pm 0.00044\end{array}$ & $\begin{array}{c}0.01758 \\
\pm 0.00044\end{array}$ & $\begin{array}{c}0.01723 \\
\pm 0.00044\end{array}$ & $\begin{array}{c}0.01650 \\
\pm 0.00044\end{array}$ & $\begin{array}{c}0.01578 \\
\pm 0.00044\end{array}$ \\
\hline \multirow{2}{*}{$7 \times 7$} & Exp. & 0.5360 & 0.0200 & 0.0196 & 0.0191 & 0.0185 & 0.0179 & 0.0172 & 0.0165 \\
\hline & GATE & $\begin{array}{c}0.53223 \\
\pm 0.00112\end{array}$ & $\begin{array}{c}0.01978 \\
\pm 0.00083\end{array}$ & $\begin{array}{c}0.01942 \\
\pm 0.00083\end{array}$ & $\begin{array}{c}0.01902 \\
\pm 0.00083\end{array}$ & $\begin{array}{c}0.01865 \\
\pm 0.00083\end{array}$ & $\begin{array}{c}0.01833 \\
\pm 0.00083\end{array}$ & $\begin{array}{c}0.01765 \\
\pm 0.00083\end{array}$ & $\begin{array}{c}0.01699 \\
\pm 0.00083\end{array}$ \\
\hline \multirow{2}{*}{$8 \times 8$} & Exp. & 0.5425 & 0.0227 & 0.0222 & 0.0216 & 0.0209 & 0.0201 & 0.0192 & 0.0183 \\
\hline & GATE & $\begin{array}{c}0.53985 \\
\pm 0.00234\end{array}$ & $\begin{array}{c}0.02191 \\
\pm 0.00058\end{array}$ & $\begin{array}{c}0.02152 \\
\pm 0.00058\end{array}$ & $\begin{array}{c}0.02109 \\
\pm 0.00058\end{array}$ & $\begin{array}{c}0.02072 \\
\pm 0.00058\end{array}$ & $\begin{array}{c}0.02036 \\
\pm 0.00058\end{array}$ & $\begin{array}{c}0.01964 \\
\pm 0.00058\end{array}$ & $\begin{array}{c}0.01894 \\
\pm 0.00058\end{array}$ \\
\hline \multirow{2}{*}{$10 \times 10$} & Exp. & 0.5547 & 0.0255 & 0.0253 & 0.0250 & 0.0247 & 0.0244 & 0.0240 & 0.0234 \\
\hline & GATE & $\begin{array}{c}0.55812 \\
\pm 0.00247\end{array}$ & $\begin{array}{c}0.02569 \\
\pm 0.00086\end{array}$ & $\begin{array}{c}0.02533 \\
\pm 0.00086\end{array}$ & $\begin{array}{c}0.02494 \\
\pm 0.00086\end{array}$ & $\begin{array}{c}0.02457 \\
\pm 0.00086\end{array}$ & $\begin{array}{c}0.02426 \\
\pm 0.00086\end{array}$ & $\begin{array}{c}0.02359 \\
\pm 0.00086\end{array}$ & $\begin{array}{c}0.02294 \\
\pm 0.00086\end{array}$ \\
\hline \multirow{2}{*}{$12 \times 12$} & Exp. & 0.5655 & 0.0292 & 0.0289 & 0.0284 & 0.0278 & 0.0273 & 0.0267 & 0.0260 \\
\hline & GATE & $\begin{array}{c}0.56704 \\
\pm 0.00171\end{array}$ & $\begin{array}{c}0.02899 \\
\pm 0.00066\end{array}$ & $\begin{array}{c}0.02864 \\
\pm 0.00066\end{array}$ & $\begin{array}{c}0.02825 \\
\pm 0.00066\end{array}$ & $\begin{array}{c}0.02788 \\
\pm 0.00066\end{array}$ & $\begin{array}{c}0.02757 \\
\pm 0.00066\end{array}$ & $\begin{array}{c}0.02691 \\
\pm 0.00066\end{array}$ & $\begin{array}{c}0.02626 \\
\pm 0.00066\end{array}$ \\
\hline \multirow{2}{*}{$15 \times 15$} & Exp. & 0.5805 & 0.0350 & 0.0347 & 0.0343 & 0.0338 & 0.0332 & 0.0327 & 0.0320 \\
\hline & GATE & $\begin{array}{c}0.58491 \\
\pm 0.00338\end{array}$ & $\begin{array}{c}0.03498 \\
\pm 0.00067\end{array}$ & $\begin{array}{c}0.03461 \\
\pm 0.00067\end{array}$ & $\begin{array}{c}0.03420 \\
\pm 0.00067\end{array}$ & $\begin{array}{c}0.03383 \\
\pm 0.00067\end{array}$ & $\begin{array}{c}0.03350 \\
\pm 0.00067\end{array}$ & $\begin{array}{c}0.03282 \\
\pm 0.00067\end{array}$ & $\begin{array}{c}0.03214 \\
\pm 0.00067\end{array}$ \\
\hline \multirow{2}{*}{$20 \times 20$} & Exp. & 0.5977 & 0.0435 & 0.0432 & 0.0428 & 0.0424 & 0.0419 & 0.0421 & 0.0405 \\
\hline & GATE & $\begin{array}{c}0.59753 \\
\pm 0.00303\end{array}$ & $\begin{array}{c}0.04366 \\
\pm 0.00062\end{array}$ & $\begin{array}{c}0.04323 \\
\pm 0.00062\end{array}$ & $\begin{array}{c}0.04277 \\
\pm 0.00062\end{array}$ & $\begin{array}{c}0.04235 \\
\pm 0.00062\end{array}$ & $\begin{array}{c}0.04198 \\
\pm 0.00062\end{array}$ & $\begin{array}{c}0.04120 \\
\pm 0.00062\end{array}$ & $\begin{array}{c}0.04044 \\
\pm 0.00062\end{array}$ \\
\hline
\end{tabular}

It is also obviously seen from these figures that increasing radiation field size increase the radiation dose from 0.0175 to $0.0436 \mathrm{~Gy}$. The result obtained from the GATE simulation are entirely consistent with the experimental result except $8 \times 8 \mathrm{~cm}^{2}$ radiation field size as showing detail in Figure 4 (b). In that field size there is a little difference between simulation and measurement. However, the percentage error differences between measurement and simulation are never calculated more than 3.5\%. The technical specification document of the external beam gamma teletheraphy system (for Co-60 machine) was defined the filed size error for collimator as $\pm 2 \mathrm{~mm}$ (Technical Specifications External Beam Data). Changing the field size in the simulation by $0.1 \mathrm{~mm}$ varies the radiation dose from 0.02182 to $0.02191 \mathrm{~Gy}$. Therefore, the difference between simulated data and measurement for $8 \times 8 \mathrm{~cm}^{2}$ radiation field size must be about the inaccuracy of the machine collimator. 


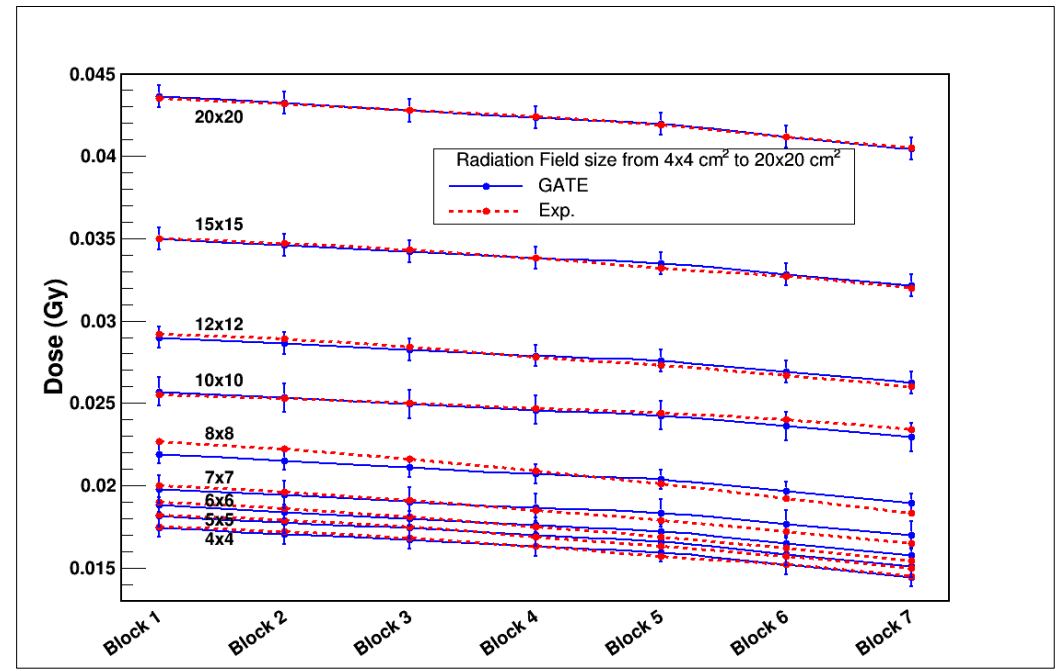

(a)

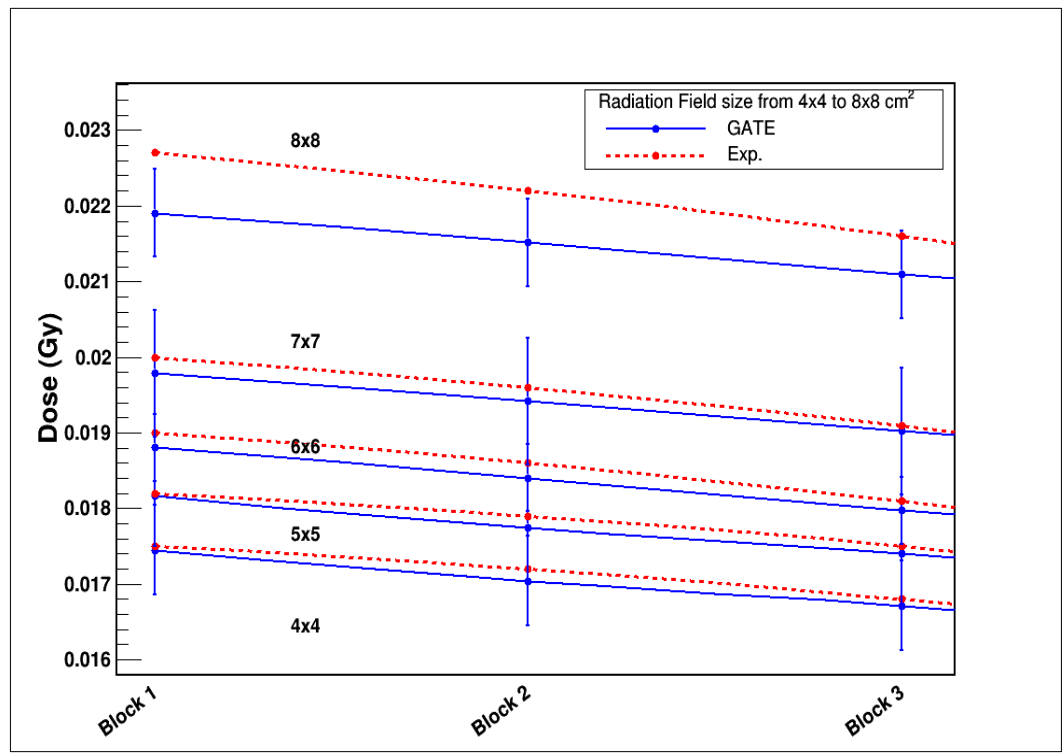

(b)

Figure 4. Comparison between experiment and GATE simulation results in different blocks and various radiation field sizes. Blue points and lines with standard deviation were acquired from the GATE simulation and red points and dash lines were represent experimental values. (a) Calculated and measured radiation doses for different blocks and field size from $4 \times 4$ to $20 \times 20 \mathrm{~cm}^{2}$ (b) the dose for $8 \times 8 \mathrm{~cm}^{2}$ field size as shown in detail. It is not completely consistent in simulation value (for $8 \times 8 \mathrm{~cm}^{2}$ field size) because of the inaccuracy of the Co60 machine collimator.

The variation of the unblocked radiation dose (open field dose) values versus the radiation field size from $4 \times 4$ to $20 \times 20 \mathrm{~cm}^{2}$, are presented in Figure 5. It can be seen in this figure that measured and simulated dose varies with the radiation field size squared. The simulated data are entirely consistent with the experimental result. 


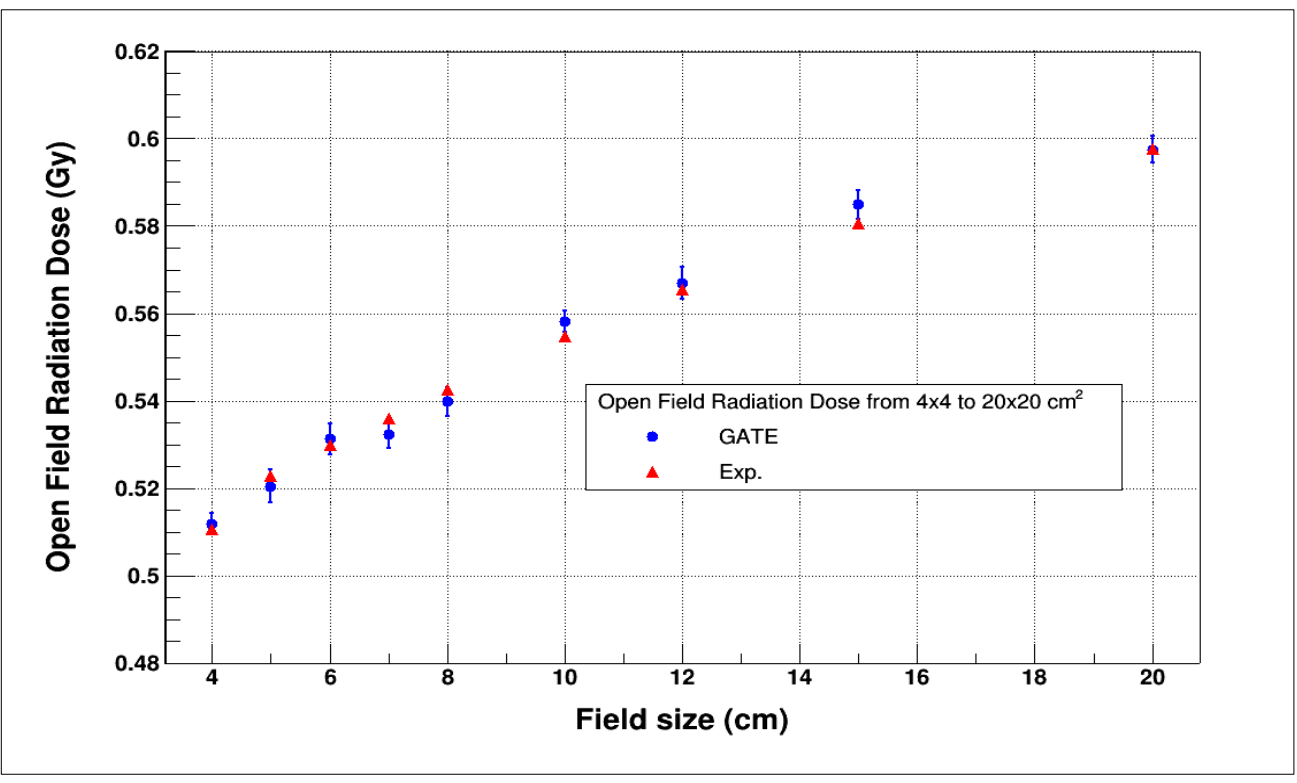

Figure 5. Comparison between experiment and GATE simulation results of the unblocked radiation dose versus to various field sizes from $4 \times 4$ to $20 \times 20 \mathrm{~cm}^{2}$. The blue points represent GATE simulation with standard deviation and red points indicate the experimental values.

Evaluated linear attenuation coefficient of the blocks are given in Table 3 for $4 x 4 \mathrm{~cm}^{2}$ radiation field size to compare simulation, measurement and theoretical values of $\mu$ and $\lambda$.

Table 3

The linear attenuation coefficients and MFP for various blocks are evaluated from simulation, experimental and theoretical results.

\begin{tabular}{|l|c|r|r|r|r|r|}
\hline Blocks & $\begin{array}{c}\boldsymbol{\mu}_{\text {xcom }}(\mathbf{a v g . ~ o f} \\
\mathbf{1 . 1 7} \mathbf{M e V} \text { and } \\
\mathbf{1 . 3 3} \\
\mathbf{M e V})\left(\mathbf{c m}^{2} / \mathbf{g}\right)\end{array}$ & $\begin{array}{c}\boldsymbol{\mu}_{\text {exp. }} \\
\left(\mathbf{c m}^{2} / \mathbf{g}\right)\end{array}$ & $\begin{array}{c}\boldsymbol{\mu}_{\text {GATE }} \\
\left(\mathbf{c m}^{2} / \mathbf{g}\right)\end{array}$ & $\lambda_{\text {xcom }}(\mathbf{c m})$ & $\lambda_{\text {exp. }}(\mathbf{c m})$ & $\lambda_{\text {GATE }}(\mathbf{c m})$ \\
\hline Block 1 & 0.5631 & 0.5623 & 0.5630 & 1.7759 & 1.7784 & 1.7762 \\
\hline Block 2 & 0.5661 & 0.5651 & 0.5670 & 1.7665 & 1.7696 & 1.7637 \\
\hline Block 3 & 0.5692 & 0.5691 & 0.5702 & 1.7569 & 1.7572 & 1.7538 \\
\hline Block 4 & 0.5739 & 0.5741 & 0.5744 & 1.7425 & 1.7419 & 1.7409 \\
\hline Block 5 & 0.5781 & 0.5804 & 0.5781 & 1.7313 & 1.7229 & 1.7298 \\
\hline Block 6 & 0.5869 & 0.5857 & 0.5862 & 1.7039 & 1.7074 & 1.7059 \\
\hline Block 7 & 0.5929 & 0.5936 & 0.5946 & 1.6866 & 1.6846 & 1.6818 \\
\hline
\end{tabular}

The theoretical calculation of the linear attenuation coefficient was determined from XCOM software via using the average values at two different gamma energies (1.17 and 1.33 MeV). Experimental, theoretical and GATE simulation findings are good agreement with each other. Besides, the variation of the linear attenuation and mean free path (MFP) with different shielding blocks are shown in Figure 6 (a and b respectively). It is obviously seen that measured and simulated values are identical with theoretical calculation (XCOM). 


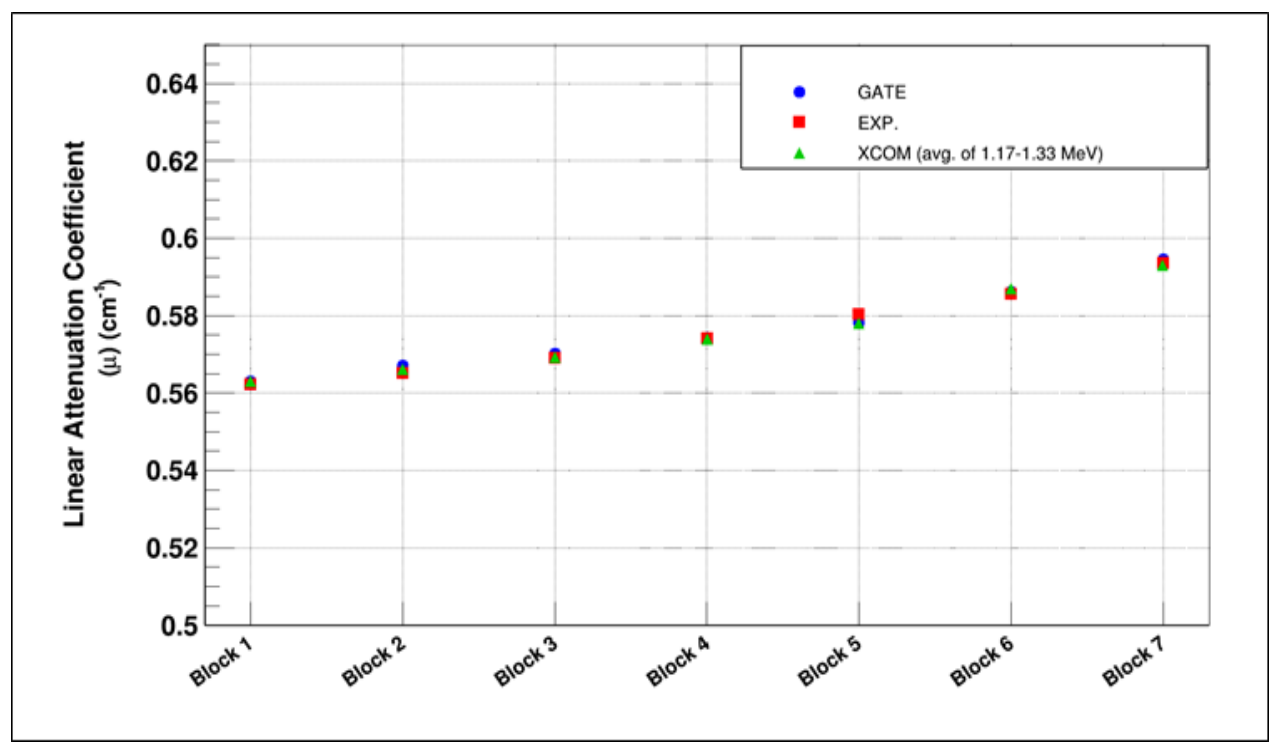

(a)

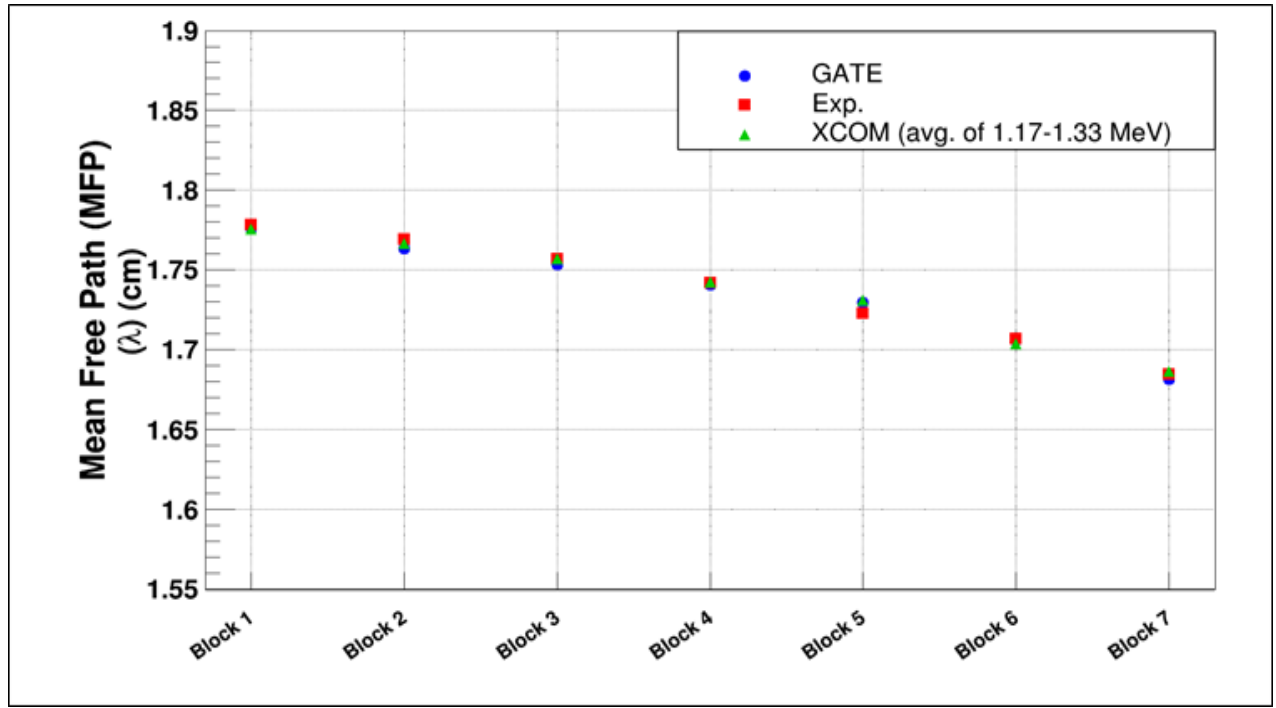

(b)

Figure 6. The comparison of simulation, experiment and theoretical values of (a) the linear attenuation coefficients $(\mu)$ and $(b)$ mean free path $(\lambda)$ for different types of blocks. Blue, red and green points represent simulation, measurement and theoretical values respectively.

In Figure 7, there is a comparison of simulation and experimental results of absorbed dose percentage for various shielding blocks at $4 \mathrm{x} 4 \mathrm{~cm}^{2}$ field size. The values of the absorbed dose percentage obtained from simulation and experiment are also compared with the pure lead block. In the simulation, the truncated square pyramid volume at the same dimension of the other blocks is defined with lead material. Calculated absorbed dose for pure lead shielding block is represented with black bars in the bar chart. It can be observed in this chart that absorbed dose increases with adding more lead marbles. As a result of that the absorbed dose of Block 7 is close to lead block's absorption level. It is also clearly seen in Figure 7 that the absorbed dose is highest at Block 7 which includes $60^{\text {th }}$ pure lead marbles. 


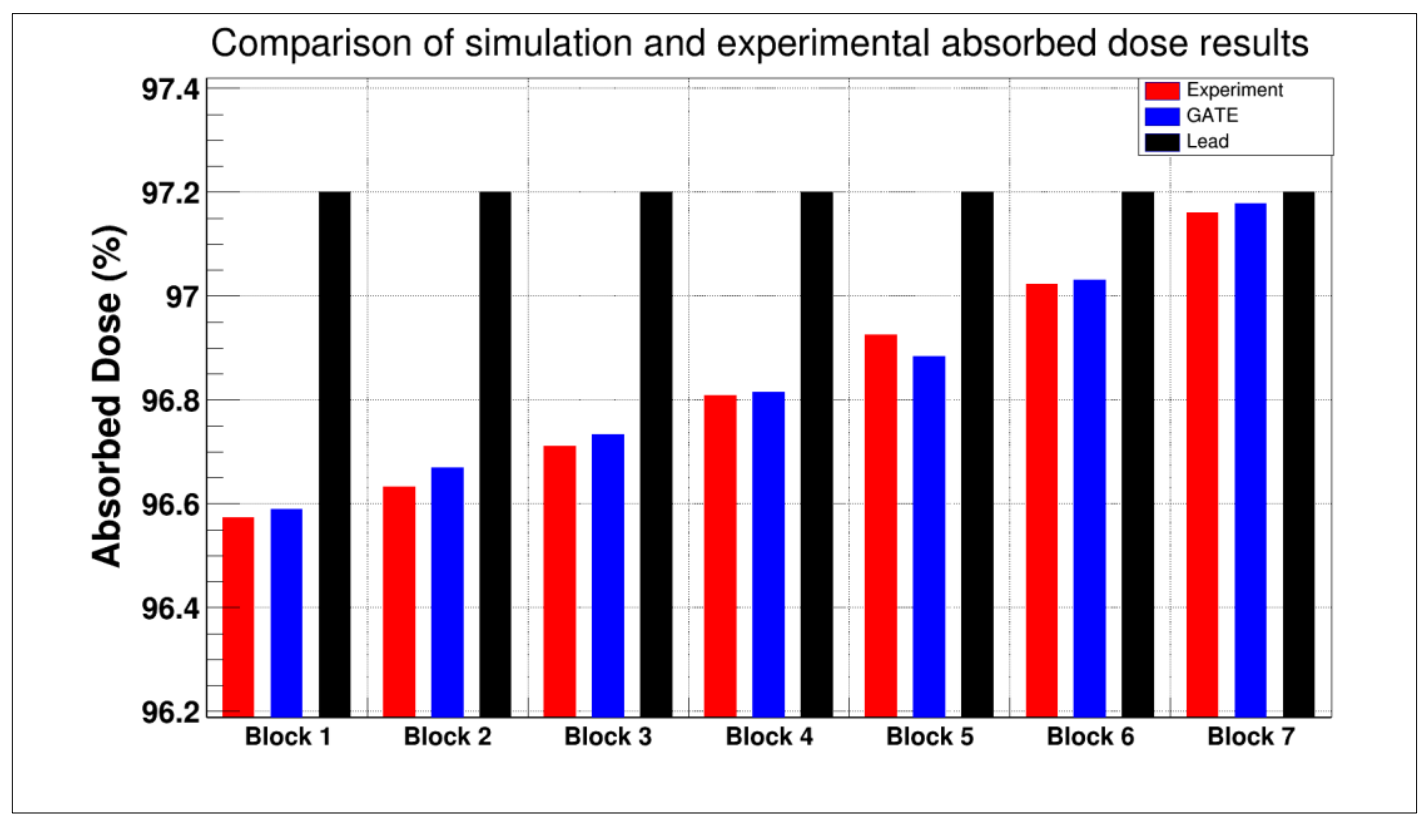

Figure 7. The comparisons of simulation and experimental absorbed dose percentage of different blocks for $4 \times 4 \mathrm{~cm}^{2}$ field size. Red bars represent measurements and blue bars indicate the GATE simulation results for each different block. Lead shielding block is defined similar geometrical shape with Cerrobend block in the simulation. The absorbed dose percentage of the lead block is shown in the bar chart with black bars.

\section{Conclusion}

This work presents simulation, experimental, and theoretical determination of linear attenuation coefficient and free mean path for different shielding blocks. The obtained results of simulation and experimental conclude in a perfect agreement with XCOM values. It can be seen the attenuation coefficient calculated from XCOM, GATE code and experiment are identical for all block samples. Block 7 has higher value of $\mu$, lower value of MFP $(\lambda)$ and higher value of the absorbed dose in percentage. It means that this block absorbs the gamma radiation more than Block 1, which is the standard Cerrobend shielding alloy commonly used in radiation therapy application. The effectiveness of shielding block used in radiotherapy will increase in the following order; Block $1<$ Block $2<$ Block $3<$ Block $4<$ Block $5<$ Block $6<$ Block 7 . It is also concluded that Cerrobend alloy with 60 pure lead marbles absorbs the maximum amount of gamma rays, which is close to pure lead block's absorption. Pure lead blocks are not practical to use in the clinics because of its higher melting points. There are many advantages to use Cerrobend alloy such as its low melting temperature, easy moulding, ease of shaping to minimize the dose outside of the treatment area, generating narrow penumbra region, low cost, and reused. This study shows that these new designed of the shielding blocks for gamma rays absorption as good as absorbed dose by lead block. It is also easy to use in the hospital conditions. In a conclusion, Block 7 can be proposed as a shielding block to provide accurately protection of the critical organs or systems inside the radiation field. New designed protection block is not only useful for radiotherapy, but it could be also used as a building material in the nuclear field, industrial field and high-energy radiotherapy facility.

\section{Acknowledgement}

Special thanks to Prof. Ayșe KAŞKAŞ for the useful hints and suggestions.

\section{Author Contributions}

Nuray Yavuzkanat: Modeling GATE simulation, analysing data and wrote the paper.

Hazal Burcu Saraç Kürem: Modelling part of the GATE simulations and collecting data. 


\section{Conflicts of Interest}

The authors declare no conflict of interest.

\section{References}

Aguwa, K. (2015). Radiation dose study in nuclear medicine using gate. Master Thesis The University of Arizona, USA. Retrieved from: https://www.optics.arizona.edu/sites/optics.arizona.edu/files/kasarachaguwa-thesis.pdf

Alkaya, F., Baş, M., Gürsoy, T. O., \& Kemikler, G. (2000). The effects of shielding blocks on dosimetry during cobalt teletherapy on irregular thorax and mediasten areas. Ankara University Tıp Fakültesi Mecmuası, 53(2), 113-119. Retrieved from: http://cms.galenos.com.tr/Uploads/Article_19110/AUTFM-53-113En.pdf

Chang, S., Zhang, Y., Dong, Y., Zhang, H. \& Dai, Y. (2012). A noval cerrobend block in the radiation therapy. Science China Technological Sciences, 55(1), 22-27. https://doi.org/10.1007/s11431-011-4559-x

Davis, J. B., \& Reiner, B. (1995). Depth dose under narrow shielding blocks: a comparison of measured and calculated dose. Radiotherapy and Oncology 34, 219-227. https://doi.org/10.1016/01678140(95)01523-J

Di Venanzio, C., Marinelli, M., Tonnetti, A., Verona-Rinati, G., Bagala, P., Falco, M. D., Guerra, A. S. \& Pimpinella, M. (2015). Comparison between small radiation therapy electron beams collimated by Cerrobend and tubular applicators, Journal of Applied Clinical Medical Physics, 16(1), 329-334. https://doi.org/10.1120/jacmp.v16i1.5186

Erk, İ., Altınsoy, N., Karaaslan, Ş. İ., \& Bora, A. (2016). Determination of Photon Mass Attenuation Coefficient for Some Phantom Materials using GATE Code and Comparison with Experimental and XCOM Data, International Journal of Nuclear and Radiation Science and Technology, 1(2), 11-13. Retrieved from: https://iakkurt.dergipark.gov.tr/ijnurasat

Farajollahi, A. R., Bouzarjomehri, F. \& Kiani, M. (2015). Comparison between Clinically Used Irregular Fields Shielded by Cerrobend and Standard Lead Blocks. Journal of Biomed Physics and Engineering, 5(2), 77-82. Retrieved from: https://www.ncbi.nlm.nih.gov/pmc/articles/PMC4479389/

Han, K., Ballon, D., Chui, C. \& Mohan, R. (1987). Monte Carlo simulation of a cobalt 60 beam. Technical reports Medical Physics, 14(3), 414-419. https://doi.org/10.1118/1.596120

Jeraj, M. \& Robar, V. (2004). Multileaf collimator in radiotherapy. Radiology and Oncology, 38(3), 235-240. Retrieved from: https://www.radioloncol.com/index.php/ro/article/view/1335

Joshi, C. P., Darko, J., Vidyasagar, P. B., \& Schreiner, L. J. (2008). Investigation of an efficient source design for Cobalt-60-based tomotherapy using EGSnrc Monte Carlo simulations. IOP Publishing, Physics in Medicine and Biology, 53, 575-592. Retrieved from: https://iopscience.iop.org/article/10.1088/00319155/53/3/005/meta

Khan, F. M. (2003). The Physics of Radiation Therapy. A Wolters Kluwer Company, (3) 154, 160-162, 273 276, Minneapolis, Minnesota.

Kürem, H. B. S. (2020). The comparision of gamma-rays transmissions between measurement and simulation obtained with the protective blocks developed as an alternative to the cerrobend blocks used in radiotherapy. Published Master Thesis, Bitlis Eren University, Physics Department, Bitlis, Turkey. Retrieved from:: https://tez.yok.gov.tr/UlusalTezMerkezi/tezSorguSonucYeni.jsp

McAlister, D. (2018). Gamma ray attenuation properties of common shielding materials. PhD Thesis, PG Research Foundation, Inc. 1955 University Lane Lisle, IL 60532, USA. Retrieved from: https://edisciplinas.usp.br/pluginfile.php/918077/mod_resource/content/1/gamma\%20ray\%20attenuati on.pdf

Mostafa, A. M. A., Issa, S. A. M. \& Sayyed, M. I. (2017). Gamma-ray shielding properties of $\mathrm{PbO}-\mathrm{B}_{2} \mathrm{O}_{3}-\mathrm{P}_{2} \mathrm{O}_{5}$ doped with $\mathrm{WO}_{3}$. Elsevier Journal of Alloys and Compounds, 708, 294-300. https://doi.org/10.1016/j.jallcom.2017.02.303 
Oliveira, A. C. H., Vieira, J. W., Santana, M. G., \& Lima, F. R. A. (2013). Monte Carlo Simulation of a Medical Linear Accelerator for Generation of Phase Spaces. International Nuclear Atlantic Conference - INAC. Retrieved from: https://inis.iaea.org/collection/NCLCollectionStore/_Public/46/015/46015552.pdf

Ozyurt, O., Altinsoy, N., Karaaslan, Ş. İ., Bora, A., Büyük, B., \& Erk, İ. (2018). Calculation of gamma ray attenuation coefficient of some granite samples using a Monte Carlo simulation code. Radiation Physics and Chemistry, 144, 271-275. https://doi.org/10.1016/j.radphyschem.2017.08.024

Perini, A. P., Neves, L. P., Fernandez-Varea, J. M., Büermann, L. \& Caldas, L. V. E. (2013). Evaluation and Simulation of a New Ionization Chamber Design for use in Computed Tomography Beams IEEE Transactions on Nuclear Science, 60(2), 768-773. Retrieved from: https://ieeexplore.ieee.org/stamp/stamp.jsp?tp=\&arnumber=6428665

Reda, S. M. (2016). Gamma ray shielding by a new combination of aluminium, iron, copper and lead using MCNP5", Arab Journal of Nuclear Science and Applications, 94(4), 211-217. Retrieved from: http://www.esnsa-eg.com/download/researchFiles/(23)\%20\%20\%20\%20\%20116-15.pdf

Sarrut, D., Bardies, M., Boussion, N., Freud, N., Jan, S., Letang, J.M., Loudos, G., Maigne, L., Marcatili, S., Mauxion, T., Papadimitroulas, P., Perrot, Y., Pietrzyk, U., Robert, C., Schaart, D., Visvikis, D. \& Buvat, I. (2014). A review of the use and potential of the GATE Monte Carlo simulation code for radiation therapy and dosimetry applications. Medical Physics, 41(6), 1-14. https://doi.org/10.1118/1.4871617

Seenappa, L., Manjunatha, H. C., Chandrika, B. M., \& Chikka, H. (2017). A Study of Shielding Properties of X-ray and Gamma in Barium Compounds. Journal of Radiation Protection and Research, 42(1), 26-32. https://doi.org/10.14407/jrpr.2017.42.1.26

Simon, R. C., Sorenson, J. A. \& Michael, E.P. (1980-2012). Physics in Nuclear Medicine. Fourth Edition, Saunders, An imprint of Elsevier Inc.

Taherkhani, A., Mohammadi, M., Saboori, M. S., \& Changizi, V. (2010). Evaluation of the physical characteristic of Cerrobend blocks used for radiation therapy. International Journal of Radiation Research, 8(2), 93-101. Retrieved from: http://ijrr.com/article-1-622-en.pdf

Tarım, U. A., \& Gürler, O. (2018). Application of Monte Carlo Method for Gamma ray Attenuation Properties of Lead Zinc Borate Glasses. Sakarya University Journal of Science, 22(6), 1848-1852. https://doi.org/10.16984/saufenbilder.443765

Technical Specifications of External Beam Gamma Teletheraphy System. Best Theratronics. Retrieved from: http://www.theratronics.ca/PDFs/BT_GB_100-80_tech_specs.pdf

Tekin, H. O., Ergüzel, T. T., Sayyed, M. I., Singh, V. P., Manıc1, T., Altunsoy, E. E. \& Agar, O. (2018). An investigation on shielding properties of different granite samples using MCNPX Code. Digest Journal of Nanomaterials and Biostructures, 13(2), 381-389. Retrieved from: https://hdl.handle.net/11492/2641

Tekin, H. O. \& Manici, T. (2017). Simulations of mass attenuation coefficients for shielding materials using the MCNP-X code. Nuclear Science and Techniques, 28(95), 1-4. Retrieved from: https://link.springer.com/article/10.1007/s41365-017-0253-4

Tellili, B., Elmahroug, Y., \& Souga, C. (2017). Investigation on radiation shielding parameters of cerrobend alloys. Nuclear Engineering and Technology, 49,1758-1777. https://doi.org/10.1016/j.net.2017.08.020

URL-1 Open Gate Collaboration, Users Guide V8. Retrieved from: http://www.opengatecollaboration.org/

Wojcicka, J. B., Yankelevich, R., Werner, B. L., \& Lasher, D. E. (2008). Technical Note: On Cerrobend shielding for 18-22 MV electron beams. Medical Physics, 35(10), 4625-4629. Retrieved from: https://pubmed.ncbi.nlm.nih.gov/18975708/

Yavuzkanat, N. (2010). The Comparison of Gamma-Rays Transmissions of Shielding Blocks with Lead Marbles and Shielding Blocks used in Radiotherapy. Published Master Thesis, Ankara University, Physics Department, Ankara, Turkey. Retrieved from: https://www.ulusaltezmerkezi.net/radyoterapidekullanilan-koruyucu-bloklar-ile-kursun-bilye-ilaveli-koruyucu-bloklarin-gama-isini-gecirgenliklerininkarsilastirilmasi/

Yorgun, N. Y. (2019). Gamma-ray Shielding Properties of Lithium Borate Glass Doped with Colemanit 


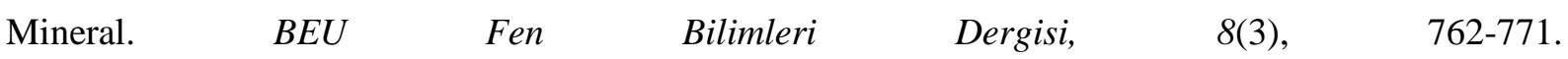
https://dergipark.org.tr/tr/pub/bitlisfen/issue/49103/525527 